\title{
Erratum zu: Motorische Entwicklung und Steuerung
}

\section{Erratum zu \\ P. Geraedts, Motorische Entwicklung und Steuerung, \\ https://doi.org/10.1007/978-3-662-58296-1}

Dieses Buch wurde versehentlich veröffentlicht, ohne die Quellen in den Bildlegenden zu aktualisieren:

\section{Kapitel 1:}

Abb. 1.1 Die korrekte Abbildungslegende lautet: Abb. 1.1 Entwicklungsverlauf koordinativer Fähigkeiten (Dordel S (1991) Bewegungsförderung in der Schule, Verlag modernes Lernen, ISBN: 3-8080-0253-0)

Abb. 1.2 Die korrekte Abbildungslegende lautet: Abb. 1.2 Entwicklung der Knochenmasse, der Muskelfläche sowie der Knochenmasse bezogen auf die Muskelfläche (Oppelt PG, Dörr H-G (2014) Kinder- und Jugendgynäkologie, Thieme Verlag ISBN: 9783131750815, mit Genehmigung)

\section{Kapitel 2:}

Abb. 2.1 Die korrekte Abbildungslegende lautet: Abb. 2.1 Extrapyramidales System: Schema der Bahnen der Willkürmotorik (Aus Spornitz 2010; Zeichnung Dr. Michael und Christiane von Solodkoff, Neckargemünd)

Abb. 2.2 Die korrekte Abbildungslegende lautet: Abb. 2.2 Pyramidales System: Schema der Bahnen der Unwillkürmotorik (Aus Spornitz
2010; Zeichnung Dr. Michael und Christiane von

Solodkoff, Neckargemünd)

\section{Kapitel 3:}

Abb. 3.1 Die korrekte Abbildungslegende lautet: Abb. 3.1 Nerv, Querdurchschnitt, VergröBerung: 2,5-fach (Aufnahme: Institut für Anatomie, Medizinische Hochschule Brandenburg)

Abb. 3.2 Die korrekte Abbildungslegende lautet: Abb. 3.2 Nervenfaserbündel, Querdurchschnitt, Vergrößerung: 20-fach (Aufnahme: Institut für Anatomie, Medizinische Hochschule Brandenburg)

Abb. 3.3 Die korrekte Abbildungslegende lautet: Abb. 3.3 Elektronenmikroskopische Aufnahmen markhaltiger Nervenfasern. Oben: Vergr. 20.000-fach. Unten: Vergr. 80.000-fach (Aus: Juncueira LC, Carneiro J (1996) Histologie, 4. Aufl. Springer Verlag. Abb. 12.18 S. 267)

Abb. 3.4 Die korrekte Abbildungslegende lautet: Abb. 3.4 Marklose Nervenfasern an der Wand einer Arteriole im Kniegelenk einer Katze. Im Bereich der Synapsen treten die Hüllzellen $(H)$ als Vorläuferzellen des Myelingewebes zurück. Zu beachten sind die synaptischen Bläschen. Vergr. 100.000-fach. (Aufnahme: Neiss W.) (Aufnahme: Neiss W.) (Aus: Juncueira LC, Carneiro J (1996) Histologie, 4. Aufl. Springer Verlag. Abb. 12.23 S. 271)

Abb. 3.6 Die korrekte Abbildungslegende lautet: Abb. 3.6 Gliederung des Rückenmar- 
squerschnittes ((Aus: Lanz von T, Wachsmuth W (2004) Praktische Anatomie - Rücken (isbn: 978-3-540-40566-5) S. 124 Abb. 130))

Abb. 3.7 Die korrekte Abbildungslegende lautet: Abb. 3.7 Querschnitte durch das Rückenmark in verschiedenen Höhen (Aus: Lanz von T, Wachsmuth W (2004) Praktische Anatomie - Rücken S.125 Abb. 131)

Abb. 3.8 Die korrekte Abbildungslegende lautet: Abb. 3.8 Plexus brachialis (Armgeflecht): Die Beteiligung der einzelnen Segmente bei der Bildung des Armgeflechts (aus: Lanz von T, Wachsmuth (2004) Praktische Anatomie - Arm (isbn: 978.3-540-40571-9) S. 32 Abb. 27)

Abb. 3.9 Die korrekte Abbildungslegende lautet: Abb. 3.9 Plexus lumbosacralis (Beingeflecht): Die Beteiligung der Segmente bei der Bildung des Plexus lumbosacralis (Aus: Lanz von T, Wachsmuth W (2004) Praktische Anatomie Bein und Statik S. 66 Abb. 41)

Abb. 3.10 Die korrekte Abbildungslegende lautet: Abb. 3.10 Reflexbogen des Eigenreflexes (Aus Spornitz 2010; Zeichnung Dr. Michael und Christiane von Solodkoff, Neckargemünd)

Abb. 3.11 Die korrekte Abbildungslegende lautet: Abb. 3.11 Reflexbogen des Fremdreflexes (Aus Spornitz 2010; Zeichnung Dr. Michael und Christiane von Solodkoff, Neckargemünd)

Abb. 3.12 Die korrekte Abbildungslegende lautet: Abb. 3.12 Schematische Darstellung einer Muskelspindel. 1 Kapsel, 2 Kernkettenfasern, 3 Kernsackfasern, 4 anulospiralige Endigung, 5 blütendoldenförmige Endigung, 6 motorische Endplatte, 7 efferente A $\gamma$-Fasern, 8 afferente A $\alpha$-Fasern, 9 afferente A $\beta$-Fasern (Aus: Juncueira LC, Carneiro J (1996) Histologie, 4. Aufl. Springer Verlag. Abb. 25.5 S. 652)

Abb. 3.13 Die korrekte Abbildungslegende lautet: Abb. 3.13 Verhalten der Bänder des Schultergelenks bei der Abduktionsbewegung des Armes. Sensoren in der Kapsel und in den Bändern nehmen diese Bewegungen war und leiten die Information weiter zum Gehirn oder lösen sofort über das Rückenmark einen Respons aus (In Auftrag von mir hergestelltes Werk, Autor: Beth Halasz, siehe Genehmigung)

Abb. 3.14 Die korrekte Abbildungslegende lautet: Abb. 3.14 a und b Der Hirnstamm mit den austretenden Hirnnerven (Aus Spornitz 2010;
Zeichnung Dr. Michael und Christiane von Solodkoff, Neckargemünd)

Abb. 3.15 Die korrekte Abbildungslegende lautet: Abb. 3.15 Aktivität der Arme, Hände und Augen (Arm-Hand-Augen-Koordination): Steuerung durch Neuronen in der Vierhügelplatte (Colliculi superiores) (@Eugene Onoshenko, Stocknr. 503978470 www.shutterstcok.com)

Abb. 3.16 Die korrekte Abbildungslegende lautet: Abb. 3.16 Der asymmetrische tonische Nackenreflex als motorische Basis für die Kletterbewegung () Monropic 66924266 stock adobe.com)

Abb. 3.17 Die korrekte Abbildungslegende lautet: Abb. 3.17 Beim Fallschirmspringen ist die Landau-Reaktion deutlich erkennbar (@) donnasterns 4238673 stock Adobe.com)

Abb. 3.18 Die korrekte Abbildungslegende lautet: Abb. 3.18 Darstellung des Kleinhirns (Aus Spornitz 2010; Zeichnung Dr. Michael und Christiane von Solodkoff, Neckargemünd)

Abb. 3.19 Die korrekte Abbildungslegende lautet: Abb. 3.19 Frontalschnitt durch das Endhirn (Aus Spornitz 2010; Zeichnung Dr. Michael und Christiane von Solodkoff, Neckargemünd)

Abb. 3.20 Die korrekte Abbildungslegende lautet: Abb. 3.20 Endhirnhemisphäre in der Seitenansicht. Vier der fünf Hirnlappen sind hier sichtbar (Aus Spornitz 2010; Zeichnung Dr. Michael und Christiane von Solodkoff, Neckargemünd)

\section{Kapitel 4:}

Abb. 4.1 Die korrekte Abbildungslegende lautet: Abb. 4.1 Muskelspindel Querdurchschnitt (Vergr.:20-fach) (Aufnahme: Institut für Anatomie, Medizinische Hochschule Brandenburg)

Abb. 4.2 Die korrekte Abbildungslegende lautet: Abb. 4.2 Vater-Pacini-Körperchen direkt unter der Haut lokalisiert (Aus: Lephart SM und Fu FH (2000) Proprioception and Neuromuscular Control in Joint Stability : Autor: Joerg G. Jerosch)

Abb. 4.3 Die korrekte Abbildungslegende lautet: Abb. 4.3 Vater-Pacini-Körperchen in glenohumeralen Bändern mit einem Durchmesser von $150 \mu \mathrm{m}$ (Aus: Lephart SM und Fu FH (2000) Proprioception and Neuromuscular Control in Joint Stability : Autor: Joerg G. Jerosch) 